\title{
Capacity measurement with the UIC 406 capacity method
}

\author{
A. Landex ${ }^{1}$, B. Schittenhelm ${ }^{1,2}$, A. H. Kaas ${ }^{3}$ \& J. Schneider-Tilli ${ }^{4}$ \\ ${ }^{I}$ Department of Transport, Technical University of Denmark, Denmark \\ ${ }^{2}$ Department of Planning, Rail Net Denmark, Denmark \\ ${ }^{3}$ Atkins Danmark A/S, Denmark \\ ${ }^{4}$ The National Rail Authority, Denmark
}

\begin{abstract}
This article describes the fast and effective UIC 406 method for calculating capacity consumption on railway lines. It is possible to expound the UIC 406 method in different ways which can lead to different capacity consumptions. Therefore, this article describes how the methodology is expounded in Denmark. This includes how and where to divide the railway lines into line sections, how to analyze stations and junctions, and how to examine line sections with different amounts of tracks.
\end{abstract}

Keywords: capacity, capacity analysis, compressed timetable graphs, timetable, UIC 406, railway, railway operation.

\section{Introduction}

The UIC 406 leaflet published in 2004 [9] describes a simple, fast and effective method for evaluating the capacity consumption of railway lines. In the past years, this method has been applied in a number of studies (e.g. [1, 10]). However, it is possible to expound the UIC 406 method in different ways, which may lead to different results.

In Denmark a number of analyzes have been conducted ([3-6]) to achieve a needed consensus between the infrastructure manager (Rail Net Denmark) and The National Railway Authority. This consensus has led to the development of a consistent method for examining railway capacity according to the UIC 406 methodology. 
This article gives a short introduction to the UIC 406 capacity method (cf. section 2) and how the method is expounded in Denmark. This includes:

- How to and where to divide the railway lines into line sections (section 3)

- How to analyze stations and junctions

- Overtaking stations (section 4.1)

- Crossing stations (section 4.2)

- Junctions (section 4.3)

- Line end stations (section 4.4)

- How to analyze line sections with one, two and multiple tracks (section 5)

At the end of the article some conclusions and perspectives of the UIC 406 method are listed (in section 6).

All the analyses presented in the article have been carried out in the timetable and simulation software RailSys [7], but could also have been carried out in other timetabling systems as e.g. TPS [2], that is used by the Danish railway agencies.

\section{The UIC 406 capacity method}

The UIC 406 method measures the capacity consumption by compressing the timetable graphs so that the buffer times [time when the infrastructure is not occupied by trains] are equal to zero, cf. Figure 1.

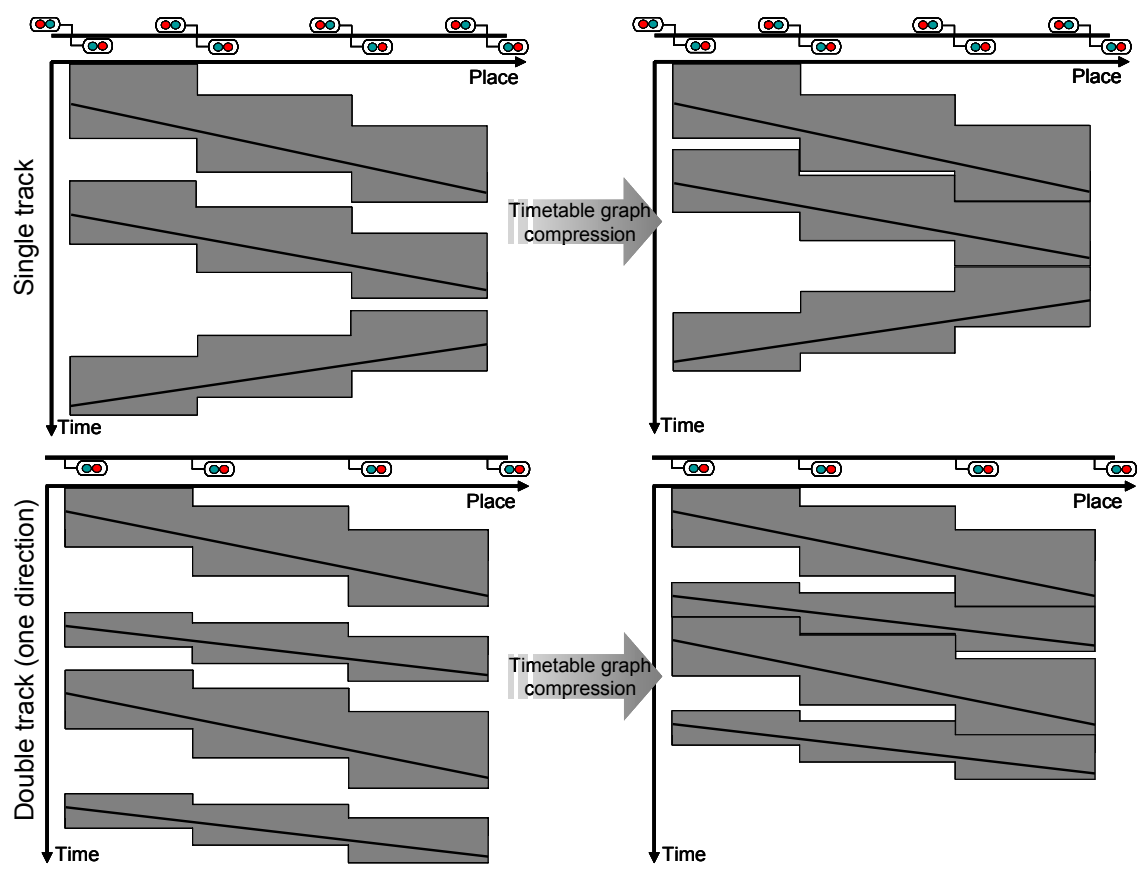

Figure 1: Compression of timetable graphs according to the UIC 406 method. 
As it is difficult, or even impossible, to compress the timetable graphs for an entire complex railway network, it is necessary to divide the network into smaller line sections that can be handled separately by the UIC 406 capacity method. Railway lines should be divided into smaller line sections at junctions overtaking stations, transition between different amount of tracks, and at crossing stations, cf. Figure 2.

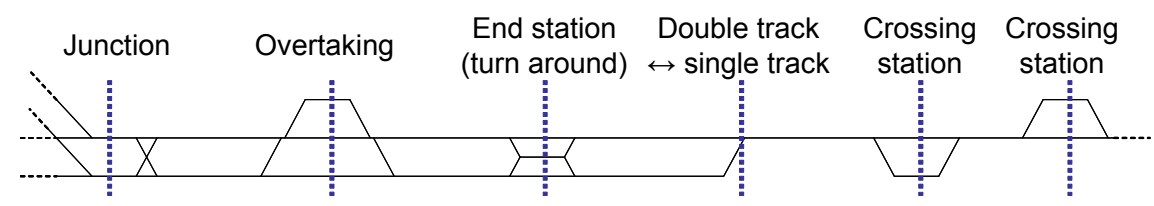

Figure 2: Division of a railway network into line sections [3, 5].

\section{Dividing the railway network into line sections}

Landex et al. [6] conclude that it is important to examine the whole railway line and not just a smaller area when capacity analyzes are carried out. However, it is not always possible to examine a whole railway line due to the lack of resources. Therefore, the effort in Denmark has been on where to divide the railway lines into line sections. In this way it is possible to compare the capacity consumptions relatively, and thus avoid false conclusions.

To avoid too many (small) line sections, and thereby the impression of having enough capacity on the railway lines although it is not true, the Danish infrastructure manager (Rail Net Denmark) and The National Railway Authority in corporation have decided only to divide the infrastructure at the following locations:

- Junctions

- Transition between double track and single track (or any other number of tracks)

- $\quad$ Line end stations (except at halts and stations that are used seldom)

A result of this strategy is that the railway lines are not necessarily divided into line sections where crossings (on single track lines) and over-takings take place, cf. Figure 3.

The deviations from the UIC 406 capacity method can be seen as rational when e.g. only few trains are overtaken at a given station. However, not following the UIC 406 methodology strictly results in challenges of how to handle takeovers, crossings and trains turning around at halts on the open line. Takeovers and crossings have been dealt with in $[3,4,6]$.

Often, trains turn around at stations but in Denmark it has been scheduled that the trains turn around at a halt on an open (single track) line (Exhibition Centre Herning). Following the guidelines of UIC 406, the line sections should have been divided into two when the number of trains changes. However, then it would be possible to compress the timetable graphs more than actually possible, and the capacity consumption would be calculated too low, cf. Figure 4. 


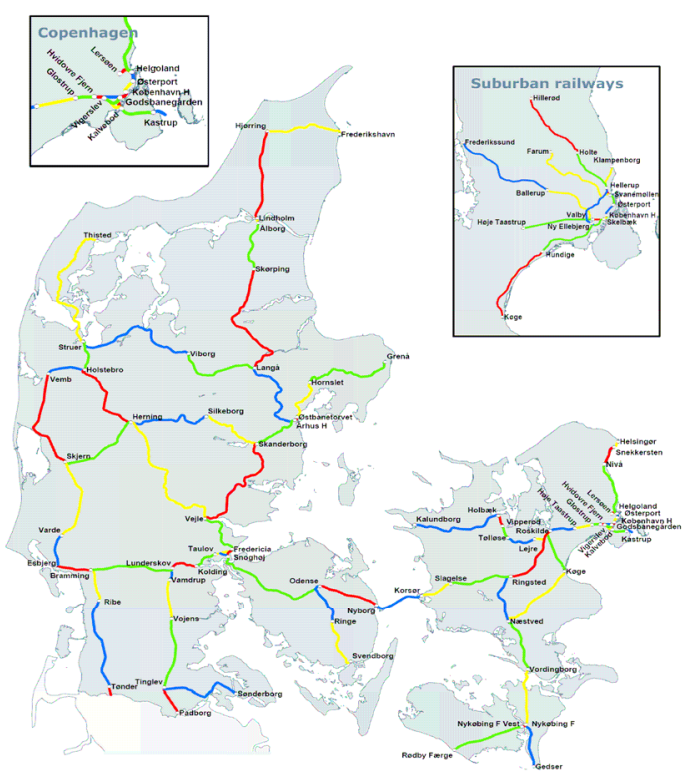

Figure 3: Dividing the Danish railway network into line sections.

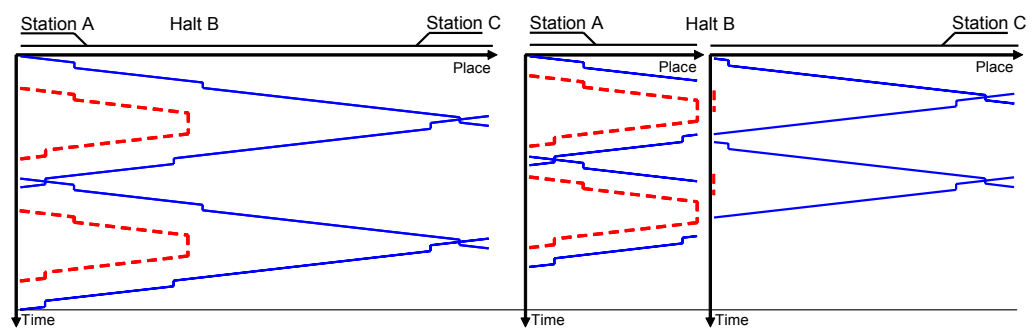

Figure 4: $\quad$ Train turning around on open (single track) line.

To compare the capacity consumption over time it is necessary not to divide into line sections at halts where trains turn around. Else, the paradox situation where less trains on the railway line would result in higher capacity consumption could occur (and vice-versa).

\section{Analyzing stations and junctions}

Stations and junctions are important for the capacity for railway lines and are to be analyzed carefully. Different results can be achieved depending on how the stations and junctions are analyzed.

\subsection{Overtaking stations}

According to the Danish interpretation of the UIC 406 method a railway line will not necessarily be divided into line sections at an overtaking station $[5,6]$. If the 
railway line is not divided into line sections at overtaking stations, there are three ways of compressing the timetable graph:

- Neither the train order nor the dwell time is changed, cf. part a in Figure 5

- The dwell time is kept but the more trains overtake the dwelling train (the train order is changed), cf. part b in Figure 5

- The dwell time is reduced to the minimum possible, but the train order is changed, cf. part c in Figure 5
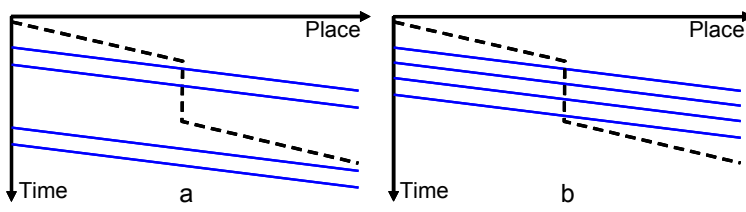

b

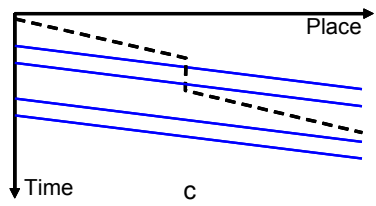

C

Figure 5: $\quad$ Timetable compression when overtaking. Based on [5].

In Denmark it has been decided that the train order should be kept at overtakings but that it is allowed to reduce the dwell time [6]. However, sufficient time to build up brake pressure after a complete halt and sufficient time for passengers to alight and board the train must be ensured.

\subsection{Crossing stations}

For single track railway lines special attention has to be paid to the crossing stations. Some crossing stations have parallel movement facilities (cf. part a in Figure 6) while other crossing stations can only handle one approaching train at the time (cf. part b in Figure 6).

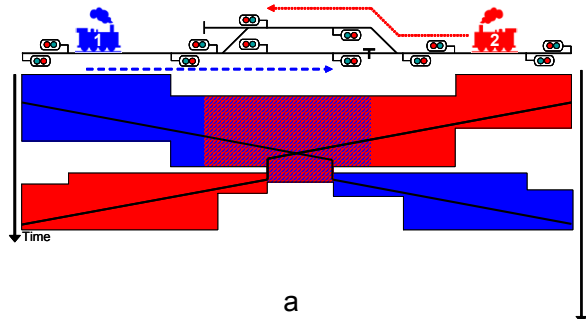

Figure 6: Crossing station with (a) and without (b) parallel movement facilities. Based on [3].

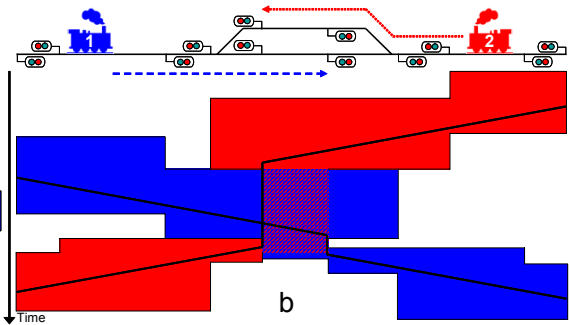

If crossing stations are able to handle parallel movement it results in less time needed, and thereby higher infrastructure capacity. The capacity gained is mainly due to reduced dwell times. The railway line should be divided into line sections at crossing stations. But, to analyze the difference in capacity consumption, it is necessary to recognize the conflicts in the far end of the crossing station by having an overlap of the two line sections [4]. 


\subsection{Junctions}

At junctions it is (just like crossing stations, cf. section 4.2) necessary to include the entire junction and the conflicting train movements to estimate the capacity.

At the junction shown in Figure 7, train route 2 may limit the capacity for two other trains running after each other on train route 1 . The reason for the "lost" capacity is that the order of the trains according to the UIC 406 leaflet should be maintained.
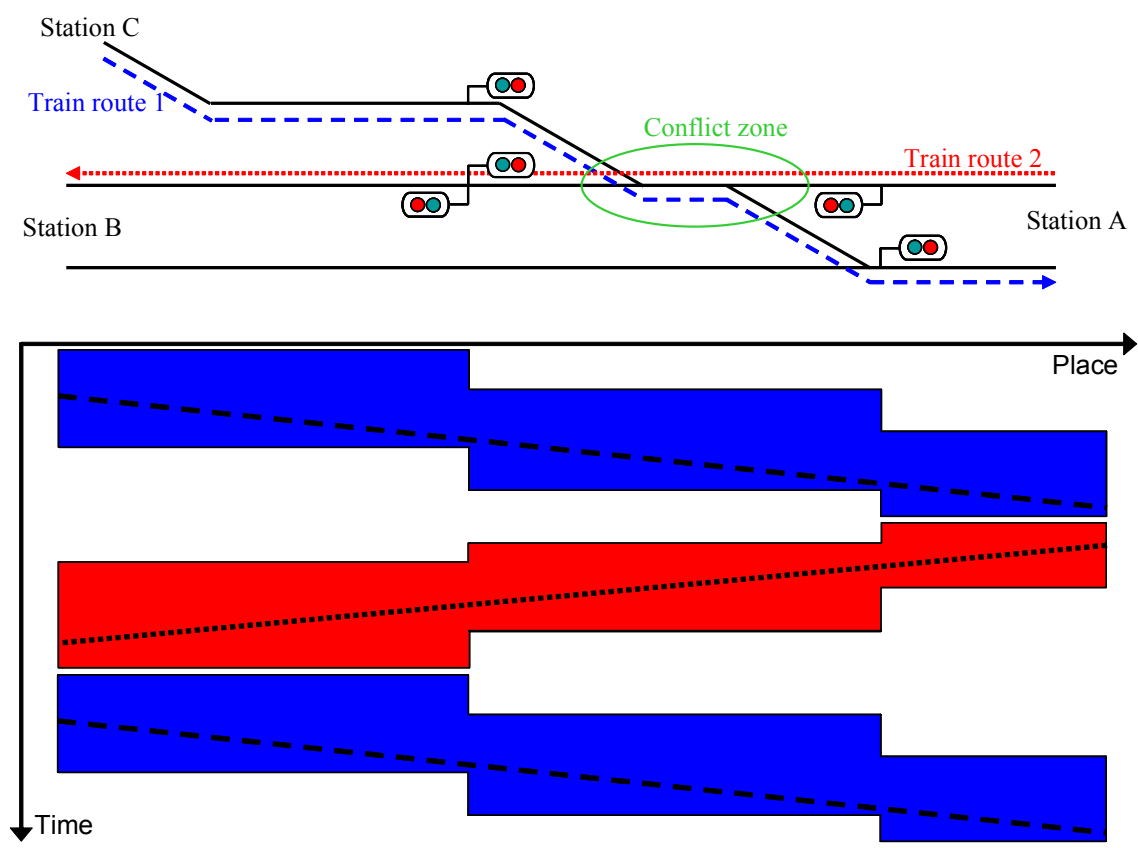

Figure 7: Capacity reduced for two trains running just after each other at a junction (only signals in use included) [3].

\subsection{Line end stations}

Trains turning around at line end stations have long dwell times that might block the train path for the following trains. To include the layover time and possible conflicts at the switch zone, the block occupation time of an arriving train should be examined all the time until it passes the exit signal on its way out of the station (or it arrives at the depot).

Trains often dwell for longer time than necessary at the avoiding track to fit into the right train path. This track blockage limits the capacity for real operation. However, to examine the infrastructure capacity only the minimum dwell/turn around time on the avoiding track, the necessary recovery time, and the train order have to be considered, cf. Figure 8. 

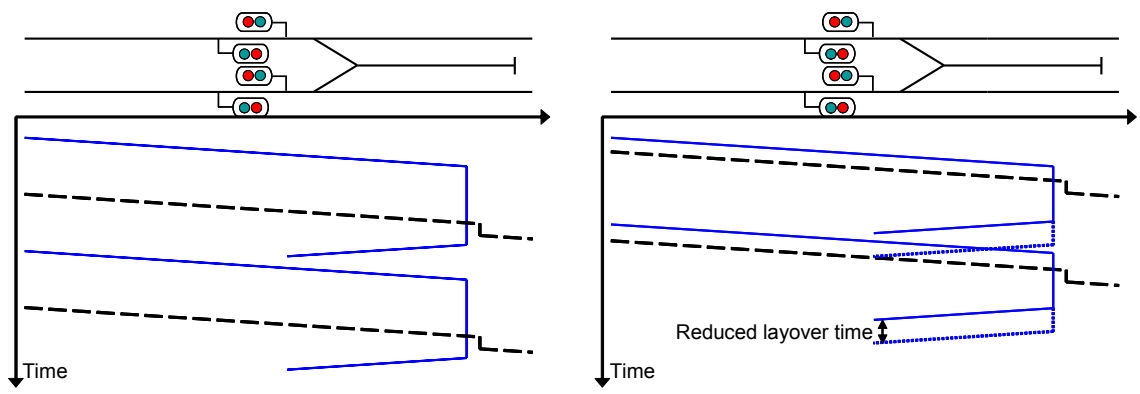

Figure 8: Compression of timetable graphs at a line end station.

Trains can be scheduled to use only one avoiding line although more avoiding lines are available (e.g. due to better transfers to busses). This may result in high capacity consumption although it is possible to operate more lines using the other avoiding line(s) too. To examine the infrastructure capacity, the trains are allowed to change between the avoiding tracks while the train order remains unchanged, cf. Figure 9.

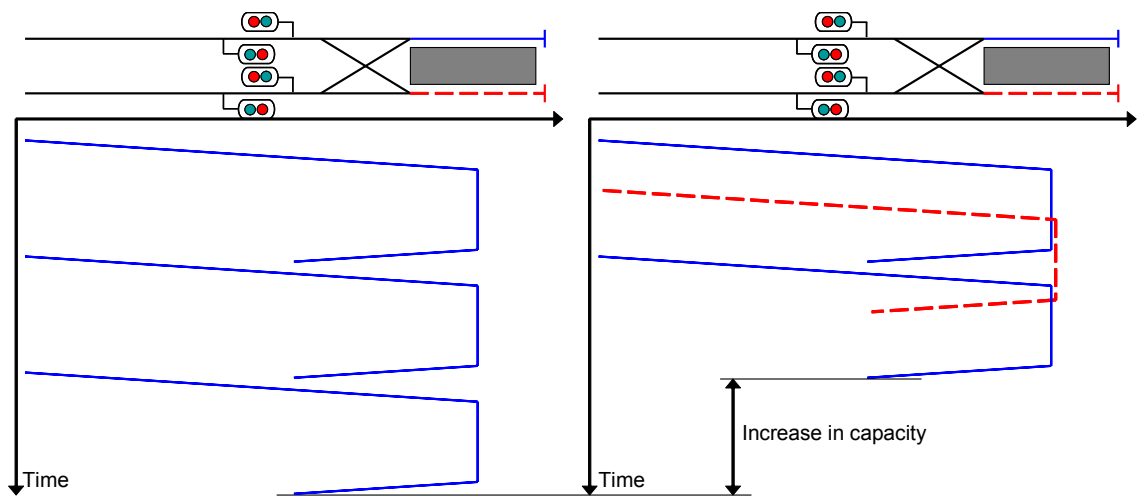

Figure 9: Increase in capacity when changing between tracks at turnarounds.

\section{Analyzing line sections with single track, double track and multiple track}

The workflow of the UIC 406 method as it is expounded in Denmark can be seen in Figure 10. First, the infrastructure to be analyzed is built up in a detailed level in a timetabling system. Then the timetable to be analyzed is established. Based on the infrastructure, the railway lines are divided into overall line sections of single track lines, double track lines, and lines with more tracks respectively. These overall line sections are then analyzed in different ways depending on the number of tracks.

Double track railway lines are the easiest to examine. The overall line sections have to be divided into line sections whereupon the timetable graphs are 
compressed according to the UIC 406 capacity method and the capacity consumption of each line section is worked out. In Denmark this division is identical to the division of the railway lines presented in Figure 3.

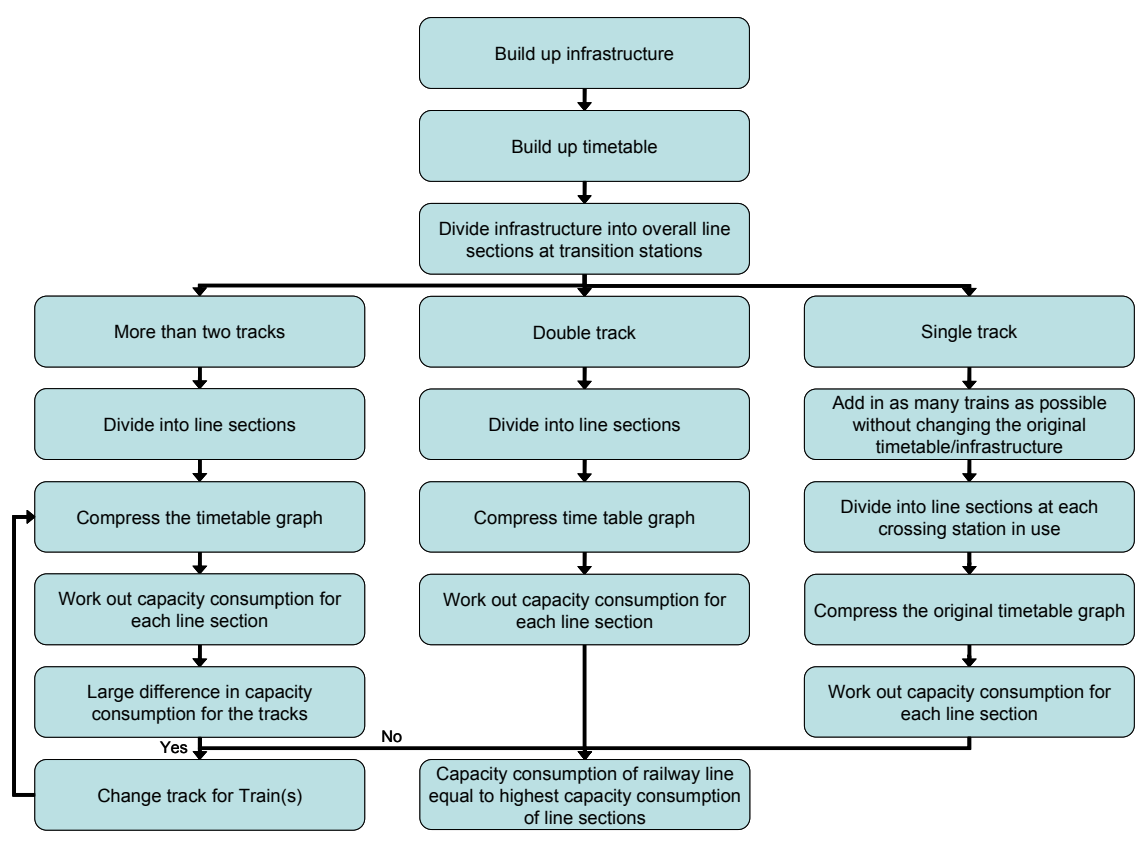

Figure 10: Workflow of measuring capacity of railway lines in Denmark.

Single track railway lines are more complicated to examine as it is necessary to add in as many trains as possible without changing the original timetable or infrastructure. The extra trains are inserted with the following priority [3]:

1. Add trains similar to the slowest train until no more trains can be added

2. Add trains similar to the second slowest train until no more trains can be added

3. Continue inserting trains ranked by their speed

4. Add trains similar to the fastest train until no more trains can be added

Each time a train is inserted in one direction, a train in the opposite direction has to bee inserted too. If it is not possible to insert a train in the opposite direction, the train in the first direction must be removed. It is only allowed to insert a train, if a conflict-free timetable can be maintained.

When the extra trains have been inserted (if any), the overall single track line section is divided into line sections for each time a crossing station is in use. Then, the timetable graph of the original timetable is compressed according to the UIC 406 capacity method and the capacity consumption of each line section is worked out (without the extra "dummy" trains).

For overall line sections containing 3, 4 or more tracks another approach has to be used. Tracks that are only used for traffic in one direction have to be 
divided into line sections the same way as double track lines, while tracks used for traffic in both directions have to be divided into line sections the same way as single track lines. The intersection of division points are then used to divide the overall line section into the final line sections. Then, the timetable graphs are compressed keeping the train order in both ends of the line section, and the capacity consumption for each line section is worked out. If it appears that there is a large difference in the capacity consumption between the tracks one or more trains have to change tracks and the compression is redone until the capacity consumption of the tracks are more or less equal [6].

The UIC 406 method is able only to calculate capacity consumption for line sections, and not for either the entire railway network or railway lines. In Denmark it has been decided that the capacity consumption of a railway line is equal to the highest capacity consumption of the line sections, cf. Figure 11 (this assumption is also made by [1], [8] and [11]). This is because most trains operate on more than one line section, and the line section that is occupied for the most time will (generally) be limiting for operating more trains.

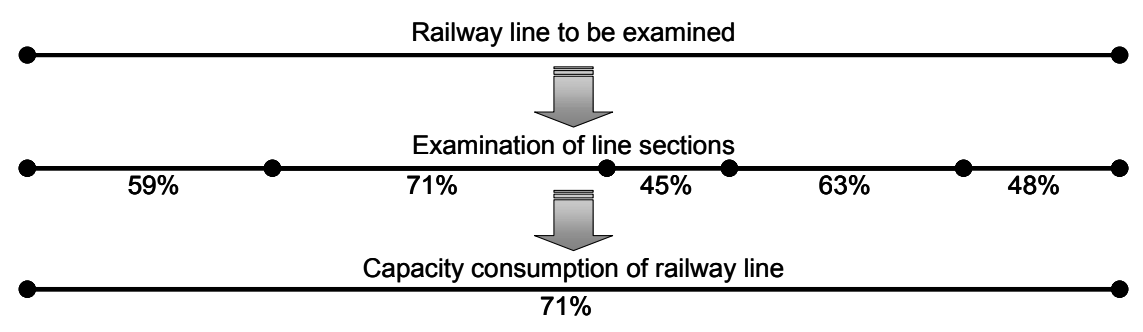

Figure 11: Working out the capacity consumption of railway lines.

\section{Conclusion and perspectives}

The UIC 406 capacity method is an easy and effective way of calculating the capacity consumption on railway lines. The method has been applied to both single track lines, double track lines and multiple track lines. Although, the UIC 406 method is straightforward, it is necessary to apply the method with diligence as the method can be expounded in different ways resulting in different results.

When using the UIC 406 method, it is important to divide the railway lines into line sections at the same locations to be able to compare the results. Therefore, it has in Denmark been decided how to and where to divide the railway network into line sections.

When conducting analyzes according to the UIC 406 method special attention has to be paid to the junctions and stations because it is often possible to expound the method in different ways here. To include potential conflicts in the far end of the station/junction, it is important to include the entire station/junction in the analyses - also if the railway line is divided into line sections here. For line end stations and overtaking stations, the dwell time might be longer than the minimum dwell time. This additional buffer time can (in the Danish methodology) be reduced. 


\section{References}

[1] Höllmüller, J. \& Klahn, V., Implementation of the UIC 406 capacity calculation at Austrian railways (ÖBB). Proc. of the $1^{\text {st }}$ International Seminar on Railway Operations Modelling and Analysis, eds. I.A. Hansen, F.M. Dekking, R.M.P. Goverde, B. Hindergott, L.E. Meester, The Netherlands, 2005

[2] Kaas, A. H. \& Goossmann, R., Implementation of the Timetable Planning System STRAX/TPS in Denmark. Proc. of the $9^{\text {th }}$ International conference on Computers in railways, eds. J. Allan, C.A. Brebbia, R.J. Hill, G. Sciutto \& S. Sone, pp. 93-102, 2004

[3] Landex, A., Evaluation of railway networks with single track operation using the UIC 406 capacity method, Networks and Spatial Economics, Accepted for publication in 2008

[4] Landex, A., Kaas, A.H., Jacobsen, E.M. \& Schneider-Tilli, J., The UIC 406 capacity method used on single track sections, Proc. of the $2^{\text {nd }}$ International Seminar on Railway Operations Modelling and Analysis, eds. I.A. Hansen, A. Radtke, J.P. Pachl, E. Wendler, Germany, 2007

[5] Landex, A., Kaas, A.H., Schittenhelm, B. \& Schneider-Tilli, J., Evaluation of railway capacity. Proc. of the Annual Transport Conference at Aalborg University, 2006

[6] Landex, A., Kaas, A.H., Schittenhelm, B. \& Schneider-Tilli, J., Practical use of the UIC 406 capacity leaflet by including timetable tools in the investigation, Proc. of the $10^{\text {th }}$ International Conference on Computers in Railways, eds. J. Allan, C.A. Brebbia, A.F. Rumsey, G. Sciutto, S. Sone \& C.J. Goodman, 2006

[7] Siefer, T. \& Radtke, A., Railway-Simulation Key for Better Operation and Optimal Use of Infrastructure, Proc. of $1^{\text {st }}$ International Seminar on Railway Operations Modelling and Analysis, eds. Hansen, I.A., Dekking, F.M., Goverde, R.M.P., Heidergott, B. \& Meester, L.E., 2005

[8] Skartsæterhagen, S., Capacity of railway lines (Kapacitet på jernbanestrekninger), Institute for energy technology, Norway, 1993 (in Norwegian)

[9] UIC leaflet 406, Capacity, UIC International Union of Railways, France, 2004

[10] Wahlborg, M., Banverket experience of capacity calculations according to the UIC capacity leaflet, Proc. of the $9^{\text {th }}$ International Conference on Computers in Railways, eds. J. Allan, C.A. Brebbia, A.F. Rumsey, G. Sciutto, S. Sone \& C.J. Goodman, 2006

[11] Yuan, J., Stochastic Modelling of Train Delays and Delay Propagation in Stations, Ph.D. thesis at Department of Transport Planning, Delft University of Technology, 2006 